\title{
Association between First Nations ethnicity and progression to kidney failure by presence and severity of albuminuria
}

Susan M. Samuel MD MSc, Luz Palacios-Derflingher PhD, Marcello Tonelli MD SM, Braden Manns MD MSc, Lynden Crowshoe MD, Sofia B. Ahmed MD MSc, Min Jun PhD, Nathalie Saad MD, Brenda R. Hemmelgarn MD PhD; for the Alberta Kidney Disease Network

See also research article by Jiang and colleagues at www.cmaj.ca/lookup/doi/10.1503/cmaj.130721 and commentary by McDonald at www.cmaj.ca/lookup/doi/10.1503/cmaj.131605

Competing interests: None declared.

This article has been peer reviewed.

Correspondence to: Brenda R. Hemmelgarn, brenda.hemmelgarn @ albertahealthservices.ca

CMAJ 2014. DOI:10.1503 /cmaj.130776

\section{ABSTRACT}

Background: Despite a low prevalence of chronic kidney disease (estimated glomerular filtration rate $[G F R]<60 \mathrm{~mL} / \mathrm{min}$ per $1.73 \mathrm{~m}^{2}$ ), First Nations people have high rates of kidney failure requiring chronic dialysis or kidney transplantation. We sought to examine whether the presence and severity of albuminuria contributes to the progression of chronic kidney disease to kidney failure among First Nations people.

Methods: We identified all adult residents of Alberta (age $\geq 18 \mathrm{yr}$ ) for whom an outpatient serum creatinine measurement was available from May 1, 2002, to Mar. 31, 2008. We determined albuminuria using urine dipsticks and categorized results as normal (i.e., no albuminuria), mild, heavy or unmeasured. Our primary outcome was progression to kidney failure (defined as the need for chronic dialysis or kidney transplantation, or a sustained doubling of serum creatinine levels). We calculated rates of progression to kidney failure by First Nations status, by estimated GFR and by albuminuria category. We determined the relative hazard of progression to kidney failure for First Nations compared with non-First Nations participants by level of albuminuria and estimated GFR.

Results: Of the 1816824 participants we identified, 48669 (2.7\%) were First Nations. First Nations people were less likely to have normal albuminuria compared with non-First Nations people $(38.7 \%$ v. $56.4 \%)$. Rates of progression to kidney failure were consistently 2- to 3-fold higher among First Nations people than among non-First Nations people, across all levels of albuminuria and estimated GFRs. Compared with non-First Nations people, First Nations people with an estimated GFR of $15.0-29.9 \mathrm{~mL} / \mathrm{min}$ per $1.73 \mathrm{~m}^{2}$ had the highest risk of progression to kidney failure, with similar hazard ratios for those with normal and heavy albuminuria.

Interpretation: Albuminuria confers a similar risk of progression to kidney failure for First Nations and non-First Nations people.
$\mathrm{S}$ evere chronic kidney disease (estimated glomerular filtration rate [GFR] $<30 \mathrm{~mL} /$ min per $1.73 \mathrm{~m}^{2}$ ) is almost 2-fold higher, and rates of end-stage kidney disease (defined as the need for chronic dialysis or kidney transplantation) are 4-fold higher, among First Nations people compared with non-First Nations people in Canada. ${ }^{1,2}$ The reasons for the higher rate of end-stage kidney disease when there is a lower prevalence of earlier stages of chronic kidney disease in First Nations people (estimated GFR 30-60 mL/min per $1.73 \mathrm{~m}^{2}$ ) are unclear. The rising incidence of diabetes is seen as the major cause of kidney failure among First Nations people; ${ }^{3}$ however, First Nations people without diabetes are also 2-3 times more likely to eventually have kidney failure. ${ }^{4}$ These observations suggest that diabetes is not the sole determinant of risk for kidney failure and that there are yet undefined factors that may accelerate the progression of chronic kidney disease in the First Nations population. ${ }^{5}$

Recent studies have highlighted the prognostic importance of albuminuria as a risk factor for kidney failure. ${ }^{6}$ Although ethnic variations in the prevalence and severity of albuminuria and their association with renal outcomes have been reported, these studies are primarily limited to non-First Nations populations. ${ }^{7}$ A limited number of studies have reported an increased preva- 
lence of albuminuria among First Nations people, suggesting the potential association between albuminuria and risk of kidney failure. ${ }^{8,9} \mathrm{We}$ sought to measure the presence and severity of albuminuria and estimate the risk of progression to kidney failure for First Nations people compared with non-First Nations people using a community-based cohort.

\section{Methods}

\section{Study design and population}

We performed a population-based cohort study of all adults 18 years of age or older in Alberta. ${ }^{10}$ We included adults for whom at least 1 outpatient serum creatinine measurement had been done for clinical care between May 1, 2002, and Mar. 31, 2008. We excluded patients who received dialysis or kidney transplant before cohort entry, or who had an estimated GFR of less than $15 \mathrm{~mL} / \mathrm{min}$ per $1.73 \mathrm{~m}^{2}$. This study was approved by the University of Calgary Conjoint Health Research Ethics Board and the University of Alberta Research Ethics Office.

\section{Classification of ethnicity}

First Nations ethnicity was determined from a First Nations status indicator variable in the Alberta Health Registry file, which identifies people registered with Aboriginal Affairs and Northern Development Canada under the Indian Act. A person with a First Nations identifier at any point in time from Apr. 1, 1994 (the earliest date of the use of the First Nations identifier in the data) to Mar. 31, 2008, was classified as First Nations; all other people were classified as nonFirst Nations. ${ }^{11}$ First Nations people in Alberta not registered under the Indian Act (that is, without a First Nations status indicator in their registry files) were classified as non-First Nations, and they account for less than $30 \%$ of Alberta's First Nations population. ${ }^{12}$

\section{Assessment of kidney function and albuminuria}

Glomerular filtration rate was estimated using the Chronic Kidney Disease Epidemiology Collaboration equation. ${ }^{13}$ The index value was categorized as follows: 90.0 or more, $60.0-89.9,45.0-59.9$, $30.0-44.9$ and $15.0-29.9 \mathrm{~mL} / \mathrm{min}$ per $1.73 \mathrm{~m}^{2}$.

Albuminuria was measured by urine dipstick on spot urine samples. For participants with multiple measurements of albuminuria, the median value was calculated from all measurements available for the 6 months before and 6 months after the index date (i.e., the date of the index estimated GFR). As in previous studies, ${ }^{14,15}$ albuminuria was categorized as normal (negative, median value of 0 ), mild (trace or +1 , median value of 1 or 2 ), heavy ( +2 or higher, median value of 3 or more) and not measured (for patients with no urine dipstick measurement during the 1-yr observation period). We chose to use albuminuria measured by urine dipstick rather than urine albumin to creatinine ratio, because urine dipstick measurements are available for more people. Furthermore, our previous work has shown that albuminuria is an important determinant of clinical outcomes, including progression to kidney failure, whether assessed by urine dipstick or urine albumin to creatinine ratio, ${ }^{14}$ supporting the validity of this measure.

\section{Measurement of sociodemographic variables and comorbidities}

Demographic data and comorbidities were obtained from health administrative data files. Neighbourhood income quintile (levels 1 [lowest] to 5 [highest]) and location of residence (urban v. rural) were defined using the participants' postal codes, which are linked to data in the 2006 Statistics Canada Postal Code Conversion File (available at www5.statcan.gc.ca/bsolc/olc-cel/olc-cel ?catno=92-153-X\&lang=eng). Aggregate neigh bourhood-level measures of income may have poor agreement with measures relying on selfreported individual household income. Nevertheless, higher incomes are associated with better health outcomes in both measures. Both measures are also comparable in their ability to identify variation in outcomes. ${ }^{16}$

Data on visits to physicians were obtained from the physicians' billing claims database. Specialist care was defined as having at least 1 outpatient visit to a nephrologist or general internist in the year before the index date. Diabetes and hypertension were identified from hospital discharge records and physicians' billing claims using validated algorithms. ${ }^{17,18}$ Comorbid conditions were defined from physician claims and hospital admissions data using validated coding algorithms and the clinical modification of the International Classification of Diseases, 9th revision, and the International Classification of Diseases, 10th revision. ${ }^{19}$ Health services data were captured for all residents of Alberta during the study period, regardless of movement within the province.

\section{Outcome measure}

Our primary outcome was progression to kidney failure, defined as the occurrence of one of the following events: chronic dialysis, renal transplantation or a sustained doubling of serum creatinine (i.e., levels twice as high as that of the index measurement for all subsequent measurements). This 
definition is often used in studies of renal outcomes. ${ }^{20}$ Participants were followed from their index date to the occurrence of the study outcome, their death (identified from the Alberta Bureau of

Table 1: Baseline characteristics of participants by First Nations status

\begin{tabular}{|c|c|c|}
\hline & \multicolumn{2}{|c|}{ Participants, \%* } \\
\hline & $\begin{array}{c}\text { Non-First Nations } \\
n=1768155\end{array}$ & $\begin{array}{c}\text { First Nations } \\
n=48669\end{array}$ \\
\hline Age, yr, median (IQR) & $47.3(24.3)$ & $39.3(21.1)$ \\
\hline Female sex & 55.6 & 59.6 \\
\hline \multicolumn{3}{|l|}{ Comorbidity } \\
\hline Diabetes & 7.1 & 12.4 \\
\hline Hypertension & 23.4 & 16.3 \\
\hline Cerebrovascular disease & 2.3 & 2.0 \\
\hline Peripheral vascular disease & 1.4 & 0.9 \\
\hline Congestive heart failure & 2.4 & 2.2 \\
\hline Cancer & 4.0 & 2.6 \\
\hline COPD & 13.5 & 23.3 \\
\hline Dementia & 1.2 & 0.7 \\
\hline Metastatic solid tumour & 0.5 & 0.4 \\
\hline Myocardial infarction & 2.1 & 1.9 \\
\hline Mild liver disease & 0.9 & 2.2 \\
\hline Moderate to severe liver disease & 0.1 & 0.3 \\
\hline Paralysis & 0.4 & 0.7 \\
\hline Peptic ulcer disease & 2.0 & 4.9 \\
\hline Rheumatic disease & 1.2 & 2.5 \\
\hline Visit to a specialist in previous year & 9.8 & 7.3 \\
\hline \multicolumn{3}{|l|}{ Location of residence } \\
\hline Rural & 18.0 & 49.0 \\
\hline Urban & 80.6 & 50.4 \\
\hline Unknown & 1.4 & 0.6 \\
\hline \multicolumn{3}{|l|}{ Income quintile } \\
\hline 1 (lowest) & 17.1 & 43.0 \\
\hline 2 & 18.0 & 14.6 \\
\hline 3 & 18.3 & 10.7 \\
\hline 4 & 20.4 & 9.0 \\
\hline 5 (highest) & 20.5 & 9.8 \\
\hline Unknown & 5.7 & 13.1 \\
\hline \multicolumn{3}{|l|}{ Albuminuria } \\
\hline Normal & 56.4 & 38.7 \\
\hline Mild & 4.4 & 6.3 \\
\hline Heavy & 0.8 & 1.3 \\
\hline Not measured & 38.5 & 53.8 \\
\hline \multicolumn{3}{|l|}{ Estimated GFR, mL/min per $1.73 \mathrm{~m}^{2}$} \\
\hline$\geq 90.0$ & 54.2 & 77.0 \\
\hline $60.0-89.9$ & 38.5 & 20.1 \\
\hline $45.0-59.9$ & 5.0 & 1.9 \\
\hline $30.0-44.9$ & 1.8 & 0.6 \\
\hline $15.0-29.9$ & 0.5 & 0.3 \\
\hline
\end{tabular}

Vital Statistics), their emigration from Alberta or the end of the study period (Mar. 31, 2009).

\section{Statistical analysis}

Baseline characteristics were described using means, medians and interquartile ranges (IQRs) or proportions. Rates of progression to kidney failure by First Nations status, estimated GFR and albuminuria were calculated using Poisson regression, adjusting for sociodemographic variables and comorbid conditions. If the Poisson assumption that the variance equals its mean was not met, a quasi-Poisson model was used. Relative hazards of progression to kidney failure comparing First Nations versus non-First Nations participants were calculated using Cox proportional hazards models, by level of albuminuria and estimated GFR. To determine whether the relationship between First Nations status and outcome varied by albuminuria level and estimated GFR, interaction terms (First Nations and albuminuria; First Nations and estimated GFR) were used. We also included an interaction term for First Nations and diabetes to determine whether the relationship of First Nations status and progression to end-stage kidney disease varied with diabetes status. We used Schoenfeld residuals to test the proportional hazards assumptions for our variables of interest. ${ }^{21}$ We repeated all analyses using competing risk proportional subdistribution hazards methods defined by Fine and Gray. ${ }^{22}$ A significance level of 0.05 was used for all statistical tests. We performed all analyses using $\mathrm{R}$ statistical software.

\section{Results}

\section{Participants}

We identified 1821619 residents of Alberta 18 years of age or older for whom least 1 outpatient serum creatinine measurement had been done during the study period. Of these residents, $78 \%$ of non-First Nations and $72.5 \%$ of First Nations patients had 1 or more creatinine measurements during follow-up. We excluded 3168 patients who had received dialysis or a kidney transplant and 1627 patients with an estimated GFR of less than $15.0 \mathrm{~mL} / \mathrm{min}$ per $1.73 \mathrm{~m}^{2}$ at the start of the observation interval. Our final cohort included 1816824 patients, 48669 (2.68\%) of whom had First Nations ethnicity.

Overall, First Nations participants were younger and more likely to live in a rural location in the lowest income quintile (Table 1) than were non-First Nations participants. The prevalence of diabetes and other comorbid conditions was higher among First Nations people than among non-First Nations people (Table 2). 
Table 2: Baseline characteristics of participants, by albuminuria and First Nations status

\begin{tabular}{|c|c|c|c|c|c|c|c|c|}
\hline \multirow{2}{*}{ Characteristic } & \multicolumn{8}{|c|}{ Albuminuria, \%* } \\
\hline & \multicolumn{4}{|c|}{ Non-First Nations participants } & \multicolumn{4}{|c|}{ First Nations participants } \\
\hline $\begin{array}{l}\text { Age, yr, } \\
\text { median (IQR) }\end{array}$ & $46.6(22.7)$ & $48.2(30.7)$ & $53.9(32.6)$ & $48.2(26.1)$ & $39.1(20.4)$ & $38.1(23.3)$ & $41.3(27.4)$ & $39.6(21.2)$ \\
\hline \multicolumn{9}{|l|}{ Comorbidity } \\
\hline Diabetes & 5.6 & 12.4 & 27.1 & 8.3 & 8.9 & 17.5 & 33.3 & 13.8 \\
\hline Hypertension & 20.5 & 30.8 & 47.1 & 26.4 & 14.3 & 19.0 & 35.3 & 16.9 \\
\hline $\begin{array}{l}\text { Cerebrovascular } \\
\text { disease }\end{array}$ & 1.6 & 3.3 & 6.1 & 3.1 & 1.5 & 2.2 & 4.1 & 2.3 \\
\hline Cancer & 3.1 & 5.2 & 6.9 & 5.2 & 2.2 & 2.8 & 3.8 & 2.8 \\
\hline COPD & 12.4 & 15.5 & 18.2 & 14.9 & 22.3 & 27.1 & 28.2 & 23.5 \\
\hline Dementia & 0.6 & 2.1 & 3.3 & 1.9 & 0.4 & 0.8 & 0.3 & 0.9 \\
\hline $\begin{array}{l}\text { Metastatic solid } \\
\text { tumour }\end{array}$ & 0.3 & 0.8 & 1.1 & 0.8 & 0.3 & 0.5 & 0.7 & 0.4 \\
\hline $\begin{array}{l}\text { Myocardial } \\
\text { infarction }\end{array}$ & 1.4 & 2.8 & 5.6 & 3.0 & 1.2 & 2.0 & 5.9 & 2.2 \\
\hline Mild liver disease & 0.7 & 1.0 & 1.5 & 1.0 & 2.0 & 2.6 & 3.6 & 2.2 \\
\hline $\begin{array}{l}\text { Moderate to severe } \\
\text { liver disease }\end{array}$ & 0.1 & 0.1 & 0.2 & 0.1 & 0.2 & 0.4 & 0.8 & 0.4 \\
\hline \multicolumn{9}{|l|}{$\begin{array}{l}\text { Location of } \\
\text { residence }\end{array}$} \\
\hline Rural & 12.9 & 19.7 & 19.0 & 25.2 & 34.2 & 48.1 & 51.7 & 59.7 \\
\hline Urban & 85.6 & 79.0 & 79.7 & 73.5 & 65.1 & 51.1 & 48.3 & 39.9 \\
\hline Unknown & 1.5 & 1.3 & 1.3 & 1.3 & 0.7 & 0.9 & 0.0 & 0.5 \\
\hline \multicolumn{9}{|l|}{ Income quintile } \\
\hline 1 (lowest) & 17.5 & 19.4 & 21.9 & 16.2 & 39.5 & 41.0 & 43.7 & 45.7 \\
\hline 2 & 18.2 & 19.0 & 20.2 & 17.5 & 17.8 & 15.7 & 12.9 & 12.2 \\
\hline 3 & 18.2 & 18.3 & 18.21 & 18.4 & 13.0 & 10.3 & 12.2 & 9.0 \\
\hline 4 & 20.9 & 19.7 & 18.0 & 19.9 & 10.5 & 8.1 & 9.4 & 7.9 \\
\hline 5 (highest) & 20.8 & 17.8 & 16.1 & 20.4 & 9.2 & 8.3 & 8.2 & 10.4 \\
\hline Unknown & 4.4 & 5.7 & 5.7 & 7.5 & 10.1 & 16.7 & 13.7 & 14.8 \\
\hline \multicolumn{9}{|l|}{$\begin{array}{l}\text { Estimated GFR, } \\
\mathrm{mL} / \mathrm{min} \text { per } 1.73 \mathrm{~m}^{2}\end{array}$} \\
\hline$\geq 90.0$ & 56.0 & 49.4 & 36.6 & 52.5 & 77.1 & 74.6 & 56.7 & 77.7 \\
\hline $60.0-89.9$ & 38.5 & 37.3 & 33.7 & 38.6 & 21.0 & 21.1 & 25.7 & 19.2 \\
\hline $45.0-59.9$ & 4.1 & 7.9 & 12.8 & 5.9 & 1.5 & 2.4 & 6.4 & 2.0 \\
\hline $30.0-44.9$ & 1.1 & 3.8 & 10.1 & 2.3 & 0.3 & 1.3 & 5.6 & 0.7 \\
\hline $15.0-29.9$ & 0.3 & 1.6 & 6.7 & 0.7 & 0.1 & 0.5 & 5.6 & 0.3 \\
\hline
\end{tabular}


A greater proportion of First Nations people $(97.1 \%)$ had an estimated GFR higher than $60.0 \mathrm{~mL} / \mathrm{min}$ per $1.73 \mathrm{~m}^{2}$ compared with nonFirst Nations people (92.7\%). First Nations people were more likely than non-First Nations people to have mild or heavy albuminuria $(7.6 \% \mathrm{v}$. $5.2 \%)$. Most First Nations people (53.8\%) had no measure of albuminuria, compared with $38.5 \%$ of non-First Nations people (Table 1).

\section{Primary outcome}

The median length of follow-up was 4.4 years for both non-First Nations and First Nations participants (IQR $2.9 \mathrm{yr}$ for non-First Nations; IQR 3.0 yr for First Nations). Chronic kidney disease progressed to kidney failure in $605(1.24 \%)$ First Nations and 10990 (0.62\%) non-First Nations participants. Among participants with an estimated GFR of more than $90.0 \mathrm{~mL} / \mathrm{min}$ per $1.73 \mathrm{~m}^{2}$ at baseline, about $20 \%$ in both groups reached the outcome of sustained doubling of creatinine, but had an estimated GFR of more than $60.0 \mathrm{~mL} / \mathrm{min}$ per $1.73 \mathrm{~m}^{2}$ by the end of the observation period.

Adjusted rates of progression to kidney failure were consistently 2- to 3-fold higher among First Nations participants than among non-First Nations participants for all levels of estimated GFR and albuminuria (Table 3). For example, among participants with an estimated GFR of $15.0-29.9 \mathrm{~mL} / \mathrm{min}$ per $1.73 \mathrm{~m}^{2}$ and mild albuminuria, adjusted rates of progression to kidney failure per 1000 person years were 20.57 (95\% confidence interval [CI] 9.85-42.94) and 9.44 (95\% CI 7.85-11.34) for First Nations and nonFirst Nations participants, respectively.

For both non-First Nations and First Nations participants, not having a measure of albuminuria was associated with rates of progression to kidney failure that were intermediate to those for normal or mild albuminuria. In addition, the lowest rates of progression to kidney failure for both groups were seen in participants with normal albuminuria, and the highest rates were seen among those with heavy albuminuria.

\section{Likelihood of progression to kidney failure}

For all levels of albuminuria and estimated GFR, the adjusted risk of progression to kidney failure was significantly greater for First Nations than for non-First Nations people (Figure 1). The greatest risk of progression to kidney failure for First Nations people was among those with an estimated GFR of $15.0-29.9 \mathrm{~mL} / \mathrm{min}$ per $1.73 \mathrm{~m}^{2}$, for whom risk was consistently 2- to 3fold higher than for non-First Nations people with a similar estimated GFR. This increased risk was present regardless of the level of albuminuria, as well as among those with no measure of albuminuria. For example, compared with non-First Nations participants, the hazard ratio for kidney failure among First Nations people with an estimated GFR of $15.0-29.9 \mathrm{~mL} / \mathrm{min}$ per $1.73 \mathrm{~m}^{2}$ was 2.92 (95\% CI 2.09-4.07) in the setting of normal albuminuria, and 2.53 (95\% CI 1.88-3.40) in the setting of heavy albuminuria. Similarly, among First Nations participants with no albuminuria measurement, the hazard ratio of progression to kidney failure was 3.22 (95\% CI 2.45-4.24).

The interactions between First Nations status and diabetes, First Nations status and albuminuria, and First Nations status and estimated GFR were not significant, suggesting that progression to kidney failure was consistently higher for First Nations than for non-First Nations participants. In analyses accounting for competing risk of death, similar patterns in risk of progression to end-stage kidney disease for First Nations and non-First Nations participants were evident. In total, 2295 (4.72\%) First Nations participants and 89357 (5.05\%) non-First Nations participants died before reaching the primary outcome.

\section{Interpretation}

We found that First Nations participants had 2to 3-fold higher rates of progression to kidney failure than non-First Nations participants, across all levels of kidney function and regardless of the presence or severity of albuminuria. Compared with non-First Nations participants, the greatest risk of progression to kidney failure for First Nations participants occurred among those with the lowest estimated GFR (15.0$29.9 \mathrm{~mL} / \mathrm{min}$ per $1.73 \mathrm{~m}^{2}$ ). These results were consistent regardless of the presence or severity of albuminuria, and after adjusting for sociodemographic characteristics, comorbidities and specialist care, as well as when death was considered as a competing risk. These results suggest that features other than those considered here contribute to the higher rates of kidney failure among First Nations people.

Our results are consistent with previous studies reporting rates of kidney failure 2- to 4-fold higher for First Nations compared with nonFirst Nations people, even among those who do not have diabetes. ${ }^{4,5,23,24}$ Similar to Dyck and colleagues, we report an age- and sex-adjusted rate of kidney failure that is 3-fold higher for First Nations than for non-First Nations people..$^{24}$ Previous studies, however, have not included an assessment of albuminuria or potential modifying effects of albuminuria on risk of progression 


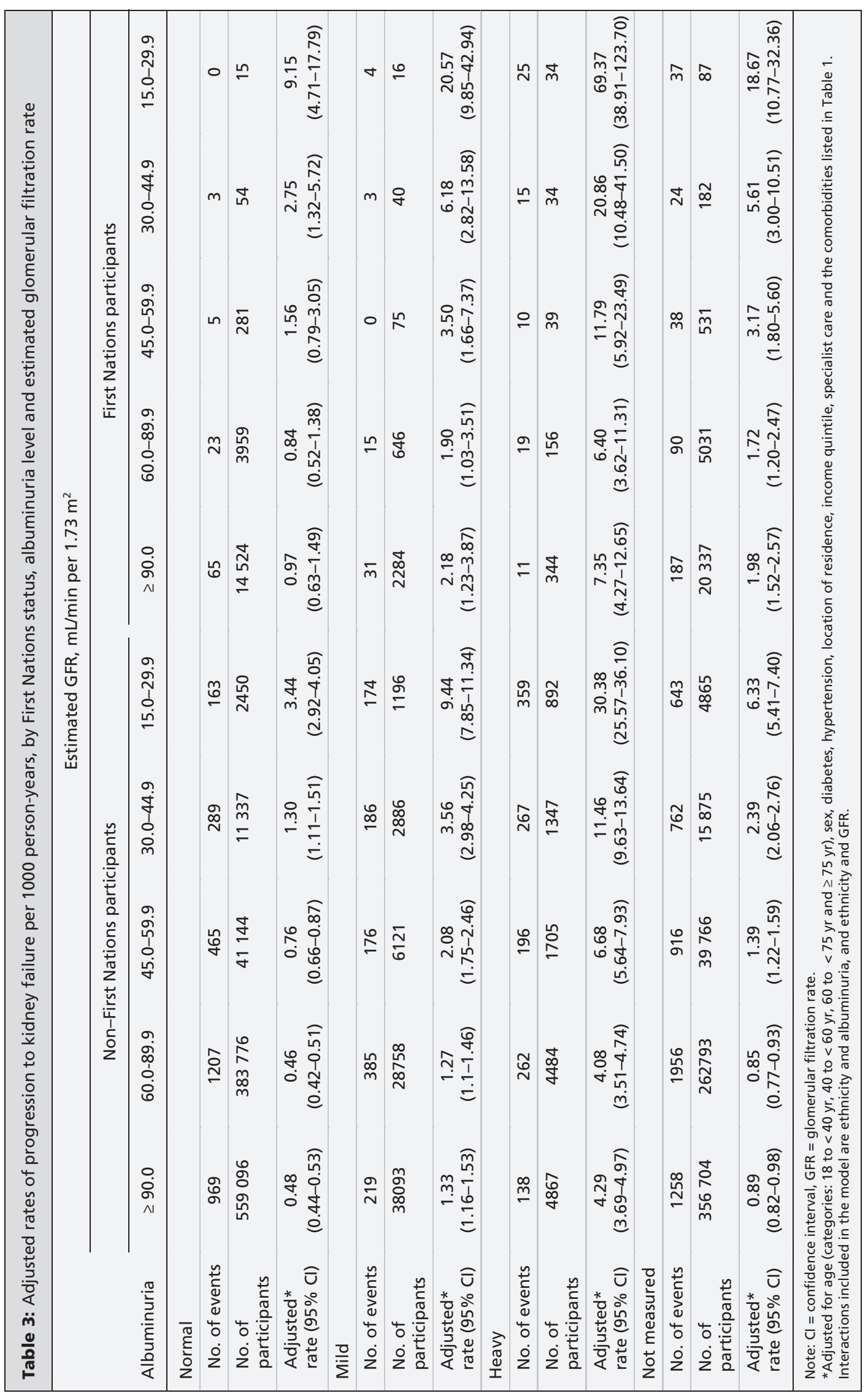


of kidney disease in this population. This is particularly relevant, given the association between albuminuria and progression to kidney failure in other populations. ${ }^{14}$

Despite a higher prevalence of heavy albuminuria among First Nations people, we did not find that the presence or severity of albuminuria conferred an additional risk to the development of kidney failure. Even among participants with no measure of albuminuria, risk of progression to kidney failure was similarly elevated for First Nations compared with non-First Nations participants within each category of estimated GFR. The increase in progression to kidney failure associated with an estimated GFR of $90.0 \mathrm{~mL} / \mathrm{min}$ per $1.73 \mathrm{~m}^{2}$ or higher, consistent for all albuminuria groups, is likely due to the relationship of reduced muscle mass (reflecting ill health) to kidney function and progression to kidney failure. ${ }^{25} \mathrm{We}$ conclude that albuminuria has no appreciable modifying effect on the association between First Nations status and progression to kidney failure. We suggest that there are unique factors relevant to First Nations people that determine progression to kidney failure, which are independent of albuminuria.

Differences in patient- or system-level factors

\begin{tabular}{|c|c|c|c|c|}
\hline Albuminuria & $\begin{array}{c}\text { Estimated GFR, } \\
\mathrm{mL} / \mathrm{min} \text { per } 1.73 \mathrm{~m}^{2}\end{array}$ & HR $(95 \% \mathrm{CI})$ & $\begin{array}{r}\begin{array}{r}\text { Decreased risk } \\
\text { of kidney } \\
\text { failure }\end{array} \\
\end{array}$ & $\begin{array}{l}\text { Increased risk } \\
\text { of kidney } \\
\text { failure }\end{array}$ \\
\hline \multirow[t]{5}{*}{ Normal } & $\geq 90.0$ & $1.95(1.56-2.42)$ & & $\longrightarrow$ \\
\hline & $60.0-89.9$ & $1.81(1.42-2.32)$ & & 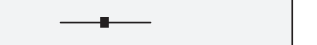 \\
\hline & $45.0-59.9$ & $2.05(1.46-2.87)$ & & - \\
\hline & $30.0-44.9$ & $2.15(1.48-3.10)$ & & \\
\hline & $15.0-29.9$ & $2.92(2.09-4.07)$ & & - \\
\hline \multirow[t]{5}{*}{ Mild } & $\geq 90.0$ & $1.61(1.20-2.16)$ & & \\
\hline & $60.0-89.9$ & $1.50(1.10-2.04)$ & & \\
\hline & $45.0-59.9$ & $1.69(1.17-2.46)$ & & \\
\hline & $30.0-44.9$ & $1.78(1.19-2.64)$ & & \\
\hline & $15.0-29.9$ & $2.41(1.66-3.50)$ & & \\
\hline \multirow[t]{5}{*}{ Heavy } & $\geq 90.0$ & $1.69(1.28-2.22)$ & & \\
\hline & $60.0-89.9$ & $1.57(1.18-2.09)$ & & \\
\hline & $45.0-59.9$ & $1.77(1.25-2.51)$ & & \\
\hline & $30.0-44.9$ & $1.86(1.32-2.63)$ & & \\
\hline & $15.0-29.9$ & $2.53(1.88-3.40)$ & & \\
\hline \multirow[t]{8}{*}{ Not measured } & $\geq 90.0$ & $2.15(1.88-2.46)$ & & \\
\hline & $60.0-89.9$ & $2.00(1.67-2.39)$ & & $\longrightarrow$ \\
\hline & $45.0-59.9$ & $2.26(1.70-3.01)$ & & $\longrightarrow$ \\
\hline & $30.0-44.9$ & $2.37(1.73-3.25)$ & & $\overline{-}$ \\
\hline & $15.0-29.9$ & $3.22(2.45-4.24)$ & & - \\
\hline & & & $T$ & 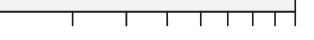 \\
\hline & & & 0.5 & 2.0 \\
\hline & & & & IR (95\% CI) \\
\hline
\end{tabular}

Figure 1: Likelihood of progression to kidney failure for First Nations participants, by estimated glomerular filtration rate and albuminuria category. The model was adjusted for age (18 to $<40 \mathrm{yr}, 40$ to $<60 \mathrm{yr}, 60$ to $<75 \mathrm{yr}$ and $\geq 75 \mathrm{yr}$ ), sex, diabetes, hypertension, location of residence, income quintile, specialist care and the comorbidities listed in Table 1. Interactions included in the model are ethnicity and albuminuria, and ethnicity and glomerular filtration rate. $\mathrm{Cl}=$ confidence interval, $\mathrm{GFR}=$ glomerular filtration rate, $\mathrm{HR}=$ hazard ratio. 
may explain our findings. First Nations people experience lower quality of care and limited access to specialist care, and present with more severe chronic kidney disease despite having a similar probability of creatinine measurement, compared with non-First Nations people..$^{26,27}$ Reduced access to specialist care for First Nations people with epilepsy has also been reported. ${ }^{28}$ Not all of the participants in our study had albuminuria measurements, with nonmeasurement more common among First Nations participants. This may represent an opportunity to improve care, because measurement of albuminuria is an indicator of overall access to care for chronic kidney disease.

\section{Limitations}

We used a community-based cohort with creatinine measurements obtained for routine clinical care, which did not include people who did not use medical services. However, we have previously reported that First Nations people are as likely as non-First Nations people to obtain a measure of serum creatinine. ${ }^{1}$

There is a potential for misclassification of albuminuria based on urine dipstick assessment, particularly when the measurement is based on a single measure. However, the percentage of participants with unmeasured proteinuria in our cohort is similar to that seen in other cohorts of patients with chronic kidney disease. ${ }^{29}$

Because we did not have information on variables such as blood pressure control, smoking status, individual income, mobility within the province, and for First Nations participants, medication use, residual confounding is possible.

Finally, we are unable to obtain further information regarding Aboriginal people (First Nations and non-First Nations) not registered under the Indian Act.

\section{Conclusion}

Our study provides important new information regarding the association of albuminuria and risk of progression to kidney failure among First Nations people, with albuminuria conferring a similar risk of kidney failure for both First Nations and non-First Nations people.

\section{References}

1. Gao S, Manns BJ, Culleton BF, et al. Prevalence of chronic kidney disease and survival among aboriginal people. J Am Soc Nephrol 2007;18:2953-9.

2. Dyck RF. Mechanisms of renal disease in indigenous populations: influences at work in Canadian indigenous peoples. Nephrology (Carlton) 2001;6:3-7.

3. Young TK, Reading J, Elias B, et al. Type 2 diabetes mellitus in Canada's First Nations: status of an epidemic in progress. CMAJ 2000;163:561-6.

4. Samuel SM, Foster BJ, Hemmelgarn BR, et al. Incidence and causes of end-stage renal disease among Aboriginal children and young adults. CMAJ 2012;184:E758-64.
5. Dyck RF, Tan L. Non-diabetic end-stage renal disease among Saskatchewan Aboriginal people. Clin Invest Med 1998;21:33-8.

6. Gansevoort RT, Matsushita K, van der Velde M, et al. Lower estimated GFR and higher albuminuria are associated with adverse kidney outcomes. A collaborative meta-analysis of general and high-risk population cohorts. Kidney Int 2011;80:93-104.

7. McClellan W, Warnock DG, McClure L, et al. Racial differences in the prevalence of chronic kidney disease among participants in the Reasons for Geographic and Racial Differences in Stroke (REGARDS) Cohort Study. J Am Soc Nephrol 2006;17:1710-5.

8. Pavkov ME, Knowler WC, Bennett PH, et al. Increasing incidence of proteinuria and declining incidence of end-stage renal disease in diabetic Pima Indians. Kidney Int 2006;70:1840-6.

9. Hoy WE, Wang Z, VanBuynder P, et al. The natural history of renal disease in Australian Aborigines. Part 2. Albuminuria predicts natural death and renal failure. Kidney Int 2001;60:249-56.

10. Hemmelgarn BR, Clement F, Manns BJ, et al. Overview of the Alberta Kidney Disease Network. BMC Nephrol 2009;10:30.

11. Population by selected ethnic origins, by province or territory (2006 census). Ottawa (ON): Statistics Canada; 2006.

12. Aboriginal peoples of Canada: highlight tables, 2001 census. Ottawa (ON): Statistics Canada; 2001. Cat. no. 97F0024XIE 2001007.

13. Levey AS, Stevens LA, Schmid CH, et al. A new equation to estimate glomerular filtration rate. Ann Intern Med 2009;150: 604-12.

14. Hemmelgarn BR, Manns BJ, Lloyd A, et al. Relation between kidney function, proteinuria, and adverse outcomes. JAMA 2010;303:423-9.

15. Lamb EJ, MacKenzie F, Stevens PE. How should proteinuria be detected and measured? Ann Clin Biochem 2009;46:205-17.

16. Southern DA, McLaren L, Hawe P, et al. Individual-level and neighborhood-level income measures: agreement and association with outcomes in a cardiac disease cohort. Med Care 2005; 43:1116-22.

17. Hux JE, Ivis F, Flintoft V, et al. Diabetes in Ontario: determination of prevalence and incidence using a validated administrative data algorithm. Diabetes Care 2002;25:512-6.

18. Quan H, Khan N, Hemmelgarn BR, et al. Validation of a case definition to define hypertension using administrative data. Hypertension 2009;54:1423-8.

19. Quan H, Sundararajan V, Halfon P, et al. Coding algorithms for defining comorbidities in ICD-9-CM and ICD-10 administrative data. Med Care 2005;43:1130-9.

20. Lambers Heerspink HJ, Perkovic V., de Zeeuw D. Is doubling of serum creatinine a valid clinical 'hard' endpoint in clinical nephrology trials? Nephron Clin Pract 2011;119:c195-99.

21. Grambsch P, Therneau T. Proportional hazards tests and diagnostics based on weighted residuals. Biometrika 1994;81:515-26.

22. Fine JP, Gray RJ. A proportional hazards model for the subdistribution of a competing risk. J Am Stat Assoc 1999;94:496-509.

23. Dyck RF, Tan L. Rates and outcomes of diabetic end-stage renal disease among registered native people in Saskatchewan. CMAJ 1994;150:203-8.

24. Dyck RF, Hayward MN, Harris SB. Prevalence, determinants and co-morbidities of chronic kidney disease among First Nations adults with diabetes: results from the CIRCLE study. BMC Nephrol 2012;13:57.

25. Matsushita K, van der Velde M, Astor BC, et al. Association of estimated glomerular filtration rate and albuminuria with allcause and cardiovascular mortality in general population cohorts: a collaborative meta-analysis. Lancet 2010;375:2073-81.

26. Shah BR, Gunraj N, Hux JE. Markers of access to and quality of primary care for aboriginal people in Ontario, Canada. Am J Public Health 2003;93:798-802.

27. Gao S, Manns BJ, Culleton BF, et al. Access to health care among status Aboriginal people with chronic kidney disease. CMAJ 2008;179:1007-12.

28. Jetté N, Quan H, Faris P, et al. Health resource use in epilepsy: significant disparities by age, gender, and Aboriginal status. Epilepsia 2008:49:586-93.

29. Hall YN, O'Hare AM, Young BA, et al. Neighborhood poverty and kidney transplantation among US Asians and Pacific Islanders with end-stage renal disease. Am J Transplant 2008;8: 2402-9.

Affiliations: Division of Paediatric Nephrology, Department of Paediatrics (Samuel), Faculty of Medicine, and Alberta Children's Hospital Research Institute for Child and Maternal Health; Faculty of Nursing and Department of Community Health Sciences (Palacios-Derflingher), Faculty of Medicine; Division of Nephrology, Department of Medicine, Faculty of Medicine, and Department of Community Health 
Sciences (Manns, Hemmelgarn), Faculty of Medicine; Department of Family Medicine (Crowshoe) and Department of Medicine (Jun), Faculty of Medicine; Department of Community Health Sciences (Samuel, Saad), Faculty of Medicine; and Division of Nephrology (Ahmed), Department of Medicine, Faculty of Medicine, University of Calgary, Calgary, Alta.; Division of Nephrology (Tonelli), Department of Medicine, Faculty of Medicine, University of Alberta, Edmonton, Alta.

Contributors: Susan Samuel, Luz Palacios-Derflingher and Brenda Hemmelgarn conceived and designed the study. Brenda Hemmelgarn, Marcello Tonelli and Braden Manns acquired the data. All of the authors analyzed and interpreted the data. Susan Samuel, Luz Palacios-Derflingher and Brenda Hemmelgarn drafted the manuscript. Brenda Hemmelgarn collected the data. All of the authors revised the article for important intellectual content and approved the final version submitted for publication.
Funding: This work was supported by an interdisciplinary team grant from Alberta Innovates - Health Solutions (AIHS) and an operating grant from the Canadian Institutes of Health Research (CIHR). Dr. Samuel is supported by salary awards from the Canadian Child Health Clinician Scientist Program and the KRESCENT Program (Kidney Foundation of Canada). Dr. Tonelli, Dr. Manns and Dr. Ahmed are supported by AI-HS Salary Awards. Dr. Tonelli is supported by a Canada Research Chair. Dr. Ahmed is supported by a salary award from CIHR. Dr. Hemmelgarn is supported by the Roy and Vi Baay Chair in Kidney Research. The funding agencies had no role in study conception, study analysis or manuscript writing.

Disclaimer: This study is based in part on data provided by Alberta Health and Alberta Health Services. The interpretation and conclusions are those of the researchers and do not represent the views of the Government of Alberta. 